\title{
An analysis of the categories regarding the probability of an operational failure of sewers
}

\author{
Emilia Kuliczkowska ${ }^{1}$, and Katarzyna Bąba ${ }^{1, *}$ \\ ${ }^{1}$ Faculty of Environmental, Geomatic and Energy Engineering, Kielce University of Technology, \\ 25 - 314 al. Tysiąclecia Państwa Polskiego 7, Poland
}

\begin{abstract}
The aim of the paper is to present proposals for the determination of the operational failure probability categories of sewers. It includes the results of a review of eleven classifications for assessing the technical condition of sewer pipes used in some countries in Europe, North America, Asia and Australia. The result of the analysis is to indicate differences between the recommendations formulated in the guidelines, resulting from the types of defects and the accepted classes. The key conclusion highlights that the application of different classification methods to assess the operational state of sewer pipes contributes to the receiving of discrepancies in their assessment. Consequently, different priorities are indicated for subsequent inspection and maintenance as well as contradictory forecasts of potential failures. The original element of the work is to present discrepancies in the assessment of three types of defects (roots, sediments, protruding connections) occurring in sewers, assessed according to selected classifications, as well as proving the necessity to undertake work aimed at determining correct recommendations, and enabling a reliable assessment of the operational condition.
\end{abstract}

\section{Introduction}

The technical condition of sewers deteriorates over time. This is influenced not only by the long-term work of sewers, the quality of materials used, the quality of workmanship, or the chemical composition of transported sewage, but also the surroundings of the pipe (eg. the condition of the ground or the way the land above the sewer is used). All these factors cause various types of defects to appear in the pipe, defined as the transition from the state of ability to the state of inability, understood as a failure to meet the requirements [1]. Sewage systems are technical systems that fulfill specific functions in a given area [2]. Their basic task is to safely transport wastewater [3] from the catchment area to the receiver. According to [1], a properly working sewer discharges the assumed amount of sewage into the receiver, it is neutral for the environment in which it is arranged and operates with the minimum (according to the state of the art) operating nuisance for the network manager.

Due to the occurrence of defects in sewers, numerous irregularities and even operational failures occur, such as clogging and blockage, or sewage disasters [4]. They are

\footnotetext{
*Corresponding author: k baba@,wp.pl
} 
distinguished by the duration, the degree of involvement of the services to their removal and the effects on the surroundings [2]. The occurrence of an emergency or construction disaster of water pipes is almost immediately noticeable (and sometimes even spectacular, as described in [5]). On the other hand, failures are not easy to observe in the sewer pipes, because often strongly cracked, deformed, or partially clogged pipes, which do not meet the requirements of tightness, still continue to drain sewage. However, their functioning negatively affects the environment - it causes pollution of the ground, groundwater and creates other hazards, for example it may cause flooding of sewage on the surface of the land above the sewer.

To avoid such irregularities, systematic sewers inspections should be subjected. Their primary task is to detect defects and then determine the reasons for their occurrence [1]. There are guidelines on the frequency of inspections. The methods for determining the priorities of inspections are presented, among others in [3]. One of the possible criteria may be the risk of sewer failure. Due to the fact that water and sewage companies have limited financial resources, which are allocated for the inspection of the technical condition of sewage systems, it is recommended to perform it first in sewers, for which the probability of failure is highest and for those that could potentially occur failure would have very serious economic consequences [6].

The purpose of the work is to present proposals for determining operational failure probability categories of sewers. The scope of the study includes the results of the review of selected eleven classifications allowing an assessment of the technical condition of sewer pipes used in some countries in Europe, North America, Asia and Australia. The effect of the analysis is to indicate differences between the recommendations formulated in the existing guidelines.

\section{Method and materials}

The most popular way to check the technical condition of sewers is to carry out CCTV inspections. The camera is placed in the pipe using the sewage well. It is controlled from the surface, moving on a trolley and passing through the inside of the pipe. During such a study, occurring defects are observed and coded, most often by means of a combination of letters and numbers, according to the adopted classification. Classifications make it possible to identify the class for the defects, which is a type of category depending on the size of the defects. Some also provide points (weight), which aim is to emphasize the seriousness of defects and the threats that they can cause (the bigger, the greater the number of points). Conducting such a procedure allows finally classifying the sewer to the appropriate class of technical condition (one of three, five or six - depending on the method), which is the general assessment of the tested pipe, sometimes indicating the estimated date of renewal or other indications concerning required interventions. The class of structural and operational state is assigned to sewer pipes. On the basis of the first one, it is possible to plan activities, such as another CCTV inspection, rehabilitation priorities or its type (eg. renovation or reconstruction), while the latter allows planning of maintenance works and exploitation such as cleaning sludge or cutting overgrown roots.

The procedures for assessing the technical condition of sewers recommended in existing classifications are very similar or identical. However, they differ in terms of the proposed defect classes and classes of construction and operational condition. The most popular methods of assessing the technical condition of sewer pipes, applied in different countries were analyzed, i.e.:

- WRc 2001, 2013 (Water Research Centre) [7-10],

- NRC 2001 (National Research Council of Canada) [10-12],

- CoE 1991 (City of Edmonton) [10], 
- $\quad$ NZPIM 2006 (New Zealand Pipe Inspection Manual) [9, 13],

- NASSCO 2015 (National Association of Sewer Service Companies) [7, 14],

- zmod. CERIU 2011 (Centre for Expertise and Research on Infrastructures in Urban Areas) [7, 15],

- $\quad$ EK 2008 (Classification of Emilia Kuliczkowska) [16],

- CSP 2015 (Concordia Sewer Protocol) [9],

- SCARD 2015 (Sewer Condition Assessment and Rehabilitation Decision Making Program) [17],

- WSAA 2002, 2006 (Water Service Association of Australia) [18]

- PN-EN 13508-2 2006 (Conditions of Drain and Sewer Systems Outside Buildings-Part 2. Visual Inspection Coding System) [19].

\section{Comparative analysis of various classifications in the field of assessing operational defects in sewers}

The subject of the risk of sewer failure was undertaken so far much less than is the case for water pipes. However, this trend has changed in recent years, as evidenced by numerous foreign [17, 20-28], as well as domestic publications [29, 30]. Among the most popular risk assessment proposals arising in Poland, eg. [31-33], are those that allow designating them as a product in the category of the probability of sewer failure and the category of the consequences of these failures. Probability categories may be equivalent to the technical condition classes of sewers, determined on the basis of accepted classification, for example: A - frequent failures, very poor technical condition, B - probable failures, poor technical condition, C - occasional failures, moderate technical condition, D - unlikely failures, improper technical condition, E - improbable failures, good technical condition. Another solution is to determine them on the basis of the defects observed in the sewers during the CCTV inspection, i.e. based on defect classes, taking for example five categories - highly unlikely, improbable, partially probable, probable to highly probable. Classes of operational failures that cause hydraulic failures and pose environmental hazards and technical condition classes proposed in existing classifications may be used to determine the order of inspections or maintenance of individual sections of sewers, as the categories of probability of operational failure.

An overview of the eleven selected classifications listed in point 2 applied in different countries, made it possible to analyze the categories of probability of failure determined in accordance with particular methods. Most of the defects indicated in them causes a reduction in the cross-section of the sewer pipe. Operational defects are divided into three, four or five classes in the classifications.

One of the frequently occurring defects in sewers is the overgrowth of roots of trees and shrubs. The WRc classification (2001) distinguishes three types of roots, i.e. fine, tap roots over $10 \mathrm{~mm}$ thick, and mass ones. The mass roots, depending on the percentage of crosssection reduction, are divided into three classes $<5 \%, 5-20 \%,>20 \%$. Similarly, in the classifications of NRC (2001), CoE (1996), and NZPIM (2006), three classes of defects are indicated for roots, i.e. $<10 \%, 10-25 \%,>25 \%$. The probability categories accepted in the EK (2008) method are: $<5 \%, 5-20 \%, 20-35 \%, 35-50 \%,>50 \%$. In the CSP (2015), five classes are divided: $<5 \%, 5-10 \%, 10-25 \%, 25-50 \%,>50 \%$. In PN EN 13508-2 classification (2006) dense roots, independent small roots and a complex mass of roots are distinguished, but no defect class proposals are given. The NASSCO classification (2015) takes into account the roots as an operational defect, however, it does not contain the division into classes according to the percentage area of the reduced cross-section. 
Another example from the group of operational defects are sediments. In the proposal of the British WRc (2001), attached and settled sediments are distinguished. Five categories of probability of failure are defined, i.e. $<5 \%, 5-20 \%, 20-50 \%, 50-75 \%,>75 \%$. In the Canadian protocols NRC (2001), CoE (1996) and New Zealand NZPIM (2006), three classes are proposed: $<10 \%, 10-25 \%,>25 \%$. The American classification NASSCO (2015) distinguishes several types of deposits, among others attached grease, attached ragging, settled fine, but the categories of probabilities are the same for them, i.e. $\leq 10 \%, \leq 20 \%$, $\leq 30 \%,>30 \%$. In European proposals - EK (2008) and Canadian CSP (2015), the defect class for debris are the same as in the case of roots. In PN EN 13508-2 (2006), the sediments are divided as in the WRc guidelines, but no probability categories proposals are presented.

The third type of defects for which the categories of probability were analyzed was incrustations. The WRc classification (2001) does not isolate defects classes for them, it only divides them into light, moderate and severe. In the NRC (2001), CoE (1996) and NZPIM (2006) proposals, the probability categories are the same as for roots and sediments. The American proposal NASSCO (2015) divides incrustations into four classes depending on the percentage reduction in the cross-section, as follows: $\leq 10 \%, \leq 20 \%$, $\leq 30 \%,>30 \%$. In the classification by E. Kuliczkowska (2008), infiltration growths are divided into five classes, i.e. class $1: \geq 50 \%$, class $2: 35-50 \%$, class $3: 20-35 \%$, class 4 : $5-20 \%$, class 5: $<5 \%$. The Canadian CSP (2015) protocol distinguishes five classes with probability sizes such as in the case of roots and debris in this classification. In PN EN 13508-2 (2006) incrustations are classified as attached deposits without providing defects classes.

The reduction of the cross-section of the sewers also causes improper laterals protruding into the interior. In the NRC (2001) and CoE (1996) methods, defects are divided into three classes: $<10 \%, 10-25 \%,>25 \%$. The classifications EK (2008) and CSP (2015) distinguish five classes. In the first of these, the following ranges are specified: class $1: \geq 50 \%$, class 2 : 35-50\%, class 3: $20-35 \%$, class $4: 5-20 \%$, class 5: $<5 \%$. In the Canadian CSP proposal (2015), as for other defects, i.e. $<5 \%, 5-10 \%, 10-25 \%, 25-50 \%,>50 \%$.

Finally, on the basis of existing defects, the classifications WRc (2001), CoE (1996), NZPIM (2006), NASSCO (2015), mod. CERIU (2011), EK (2008), CSP (2015), SCARD (2015) and WSAA (2006) give sewers one of five classes of technical condition, where class 1 represents the pipe in the best condition, while class 5 at the worst. Only the EK classification (2008) uses the reverse grading. The WSAA (2002) method allows assigning one of three, and the NRC guidelines (2001) one of six (0 - 5) operational condition classes. The classification of PN EN 13 508-2 (2006) does not provide a proposal for the division into technical condition classes.

\section{Results and discussion}

The analyzed classifications differ in terms of types of operational defects analyzed, the classes adopted for them and the number of final classes of technical condition. Moreover, as previously indicated, the guidelines of PN EN 13 508-2 (2006) do not provide proposals for classifying defects and classes of technical condition These classifications also indicate other additional defects from the exploitation group, i.e. the WRc classification (2001), apart from those mentioned in point 3, indicates: other obstacles and infiltration, for which it does not propose a determination of the category of probability. The latest WRc classification proposal (2013) further details the exfiltration (visible leakage of all or part of the flow out of the pipe through a defect or faulty joints or porous area of sewer wall), penetration of the soil into the pipe, water level and line (visible deviation in sewer line). The classification of NRC (2001), also mentions infiltration - gives the method of the 
inflow of groundwater (seeping, dripping, running, trickling, gushing or spurting) and points (weights). The same is true for the next proposal - the Canadian CoE (1996). The NZPIM (2006) method additionally indicates obstacles and obstructions. The American method NASSCO (2015) lists, among the operational defects, additional infiltration (with the method and place of the inflow of water), obstacles and obstructions and the occurrence of pests (rats, cockroaches and others). The Canadian CSP classification (2015) indicates infiltration, obstacles and ground penetration, along with the probability categories, as for other failures that reduce the cross-section. The proposal [16] indicates much more defect from the hydraulic and operational group. Except for those mentioned in point 3, these are additional defects: obstacles, other pipes in the sewers, incorrect connection, infiltration into the interior of the pipe, chipping of pipes at joints, transverse or factory displacements of shape, longitudinal extensions and protruding sealing. The EK classification (2008) is therefore the most detailed.

The occurrence of these differences means that an assessment of the operational condition based on these methods may be divergent. A comparison of the category of operational failure probabilities adopted on the basis of selected classifications is presented in Table 1. It lists the categories of probability for operational failure for three types of operational defects, i.e. roots, sediments and protruding laterals. Depending on the size of the defect (from less than a $5 \%$ to $100 \%$ reduction of the cross-section) and the assigned points (weights), the operational state class was assigned (for maximum point values). For example, assuming that the largest defect that occurred in the sewer was roots, which reduced the cross section by less than $5 \%$, this defect was attributed to 2 points. According to the WRc guidelines (2001), the maximum point value equal to 2 gives the third class of operational state, which is presented in Table 1 (similarly it was done in other cases). According to the WRc classification (2001), CoE (1996), NZPIM (2006), this is a sewer in moderate condition, according to NRC (2001) and EK (2008) - in good condition, and according to the CSP (2015) - in an excellent state. For the EK (2008) classification, the grading order of the technical condition classes has been changed to allow a comparison.

Table 1 shows that, for example, overgrowing tree roots, resulting in a reduction of the cross-section by approximately $30 \%$, according to the WRc (2001) and NZPIM (2006) belong to the 5th class of operational state, and according to the CSP (2015) - up to the 4th grade. According to the CoE (1996) and EK (2008) classifications, a class 3 of the sewer operational condition is given.

The assessment of the operational condition of the sewer is as important as the assessment of the structural condition, and is unfortunately often overlooked. The problem of discrepancies in such an assessment based on different classifications is worth illustrating using specific examples. Table 2 presents descriptions of defects occurring in the tested sewers and the final class of operational condition, assigned according to selected classifications. For the classification EK (2008), the class is given in brackets according to gradation in other methods to allow comparison.

Table 2 shows the differences obtained in assigning operational state classes to sewer pipes depending on the selected maximum defect from the exploitation group. For roots, an exemplary defect observed in the pipe with a diameter of $200 \mathrm{~mm}$ has been presented. According to the five classifications (WRc 2001, CoE 1996, NZPIM 2006, EK 2008, CSP 2015), the given operational state classes sometimes differed even by two.

Differences in the assessment of the size of deposits in the pipe with a diameter of 350 $\mathrm{mm}$ are also presented. The classes assigned according to six different classifications were compared: WRc 2001, CoE 1996, NZPIM 2006, NASSCO 2015, EK 2008, CSP 2015. It was observed that for a defect of the same size, the class was given a range from 2 to 4 .

Another operational defect that can be observed in the sewer is the services protruding into the interior. Table 2 presents an example of a defect of this type that occurred in a 150 
$\mathrm{mm}$ diameter pipe. In the case of a reduction of the cross section by about $70 \%$ according to CoE 1996, EK 2008, CSP 2015, classes 3 or 5 were assigned.

Table 1. A comparison of the recommended categories of the probability for operational failure of sewers for three selected defects from the group of operational defects according to selected methods of their evaluation.

\begin{tabular}{|c|c|c|c|c|c|c|c|c|c|c|c|c|c|c|c|c|c|c|c|c|c|}
\hline \multirow{3}{*}{ 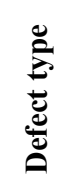 } & \multirow{3}{*}{ 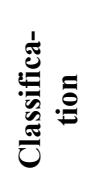 } & \multicolumn{20}{|c|}{ Category of operational failure probability } \\
\hline & & \multicolumn{20}{|c|}{ percentage of cross-section reduction } \\
\hline & & $n$ & 으 & $\cong$ & 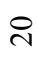 & 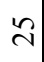 & in & $\tilde{n}$ & 우 & 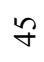 & in & $i$ & 8 & $\approx$ & R & $\stackrel{n}{2}$ & $\infty$ & $\infty$ & \& & 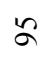 & 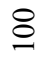 \\
\hline \multirow{6}{*}{ 参 } & WRe & 3 & & 3 & & \multicolumn{16}{|c|}{5} \\
\hline & NRC & \multicolumn{2}{|c|}{1} & \multicolumn{3}{|c|}{4} & \multicolumn{15}{|c|}{5} \\
\hline & $\mathrm{CoE}$ & \multicolumn{2}{|c|}{2} & \multicolumn{3}{|c|}{2} & \multicolumn{15}{|c|}{3} \\
\hline & $\begin{array}{c}\text { NZ } \\
\text { PIM }\end{array}$ & \multicolumn{2}{|c|}{2} & \multicolumn{3}{|c|}{4} & \multicolumn{15}{|c|}{5} \\
\hline & EK & 1 & \multicolumn{3}{|c|}{2} & \multicolumn{3}{|c|}{3} & \multicolumn{3}{|c|}{4} & \multicolumn{10}{|c|}{5} \\
\hline & CSP & 1 & 2 & \multicolumn{3}{|c|}{3} & \multicolumn{5}{|c|}{4} & \multicolumn{10}{|c|}{5} \\
\hline \multirow{7}{*}{ 䒾 } & WRc & 2 & \multicolumn{3}{|c|}{3} & \multicolumn{6}{|c|}{4} & \multicolumn{4}{|c|}{4} & & & \multicolumn{3}{|c|}{5} & \\
\hline & NRC & \multicolumn{2}{|c|}{3} & & 4 & & & & & & & & & 5 & & & & & & & \\
\hline & $\mathrm{CoE}$ & & 2 & & 2 & & & & & & & & & 3 & & & & & & & \\
\hline & $\begin{array}{c}\text { NZ } \\
\text { PIM }\end{array}$ & & 3 & & 4 & & & & & & & & & 5 & & & & & & & \\
\hline & $\begin{array}{c}\text { NASS } \\
\text { CO }\end{array}$ & & 2 & 3 & & 4 & & & & & & & & 5 & & & & & & & \\
\hline & EK & 1 & & 2 & & & 3 & & & 4 & & & & & & 5 & & & & & \\
\hline & CSP & 1 & 2 & & 3 & & & & 4 & & & & & & & 5 & & & & & \\
\hline & NRC & & & & 4 & & & & & & & & & 5 & & & & & & & \\
\hline : $\frac{a}{\pi}$ & $\mathrm{CoE}$ & & & & 2 & & & & & & & & & 3 & & & & & & & \\
\hline$\overline{0}$ & EK & 1 & & 2 & & & 3 & & & 4 & & & & & & 5 & & & & & \\
\hline & CSP & 1 & 2 & & 3 & & & & 4 & & & & & & & 5 & & & & & \\
\hline
\end{tabular}

Table 2. Discrepancies in the category of operational failure probability of sewers adopted on the basis of operational condidtion.

\begin{tabular}{|c|c|}
\hline Description of the defect & $\begin{array}{l}\text { Operational condition } \\
\end{array}$ \\
\hline $\begin{array}{l}\text { Overgrowing roots, reduction of the } \\
\text { cross-section approximately } 30 \% \\
\text { (diameter of } 200 \mathrm{~mm} \text { ) }\end{array}$ & $\begin{array}{l}\text { WRc 2001: } 5 \text { class (failure condition) } \\
\text { CoE 1996: } 3 \text { class (poor condition) } \\
\text { NZPIM 2006: } 5 \text { class (fail condition) } \\
\text { EK 2008: } 3 \text { class (necessary intervention in the } \\
\text { medium-term) } \\
\text { CSP 2015: } 4 \text { class (poor condition) }\end{array}$ \\
\hline $\begin{array}{l}\text { Solid sediment, cross-sectional reduction } \\
\text { of approximately } 15 \% \\
\text { (diameter of } 350 \mathrm{~mm} \text { ) }\end{array}$ & $\begin{array}{l}\text { WRc 2001: } 3 \text { class (poor condition) } \\
\text { CoE 1996: } 2 \text { class (fair condition) } \\
\text { NZPIM 2006: } 4 \text { class (poor condition) } \\
\text { NASSCO 2015: } 3 \text { class (fair condition) } \\
\text { EK 2008: } 4 \text { class ( } 2 \text { class) (necessary intervention in } \\
\text { the long-term) } \\
\text { CSP 2015: } 3 \text { class (fair condition) }\end{array}$ \\
\hline
\end{tabular}




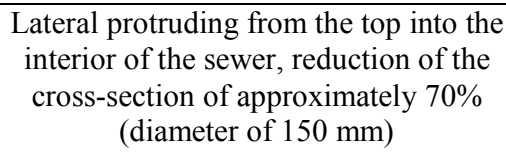

CoE 1996: 3 class (poor condition)

EK 2008: 1 class (5 class) (immediate intervention

required)

CSP 2015: 5 class (failure condition)

The presented examples show that there are significant discrepancies in the assessment of the operational condition of sewers depending on the size of defects occurring in them. This translates directly into differentiation of recommendations regarding the subsequent inspections of pipes and maintenance and operation activities planned by water and sewage companies, as well as the determination of various categories of probability for operational failure.

\section{Conclusions}

Many classifications are used to assess the technical condition of sewers, which as a result of their use unevenly assess their operational state. The adoption of the category of operational failure probability based on different classifications leads to the establishment of different recommendations regarding both the date of subsequent inspections of pipes and the maintenance and operation activities planned by the water and sewage companies.

It would be advisable to standardize the classification to assess the operational state, which would allow for the comparison of the condition of sewers in individual countries. Therefore, it is justified to continue the work that will allow an indication on the classification, which will enable a reliable assessment of the operational condition of the sewer.

In addition, using the selected classification for the technical condition of the sewers, it is necessary to take into account local conditions, including the function of the pipe (side, collector), its positioning (rectilinear, route bends), the slope (whether the minimum is maintained), and the filling (full-section or partial operation - sewer overloaded or unloaded).

When assessing the likelihood of a type of failure like clogging or blockages, it would also be advisable to note the exact location of the defect, which was partially introduced in some classifications (eg. NASSCO). It should be noted, for example, whether the root overgrowth occurs under the ceiling or on the sides, whether the sediments are deposited in the lower part of the cross-section where sewage flows or under the ceiling (eg. fats).

\section{References}

1. C. Madryas, B. Przybyła, L. Wysocki, Badania i ocena stanu technicznego przewodów kanalizacyjnych (Dolnośląskie Wydawnictwo Edukacyjne, Wrocław, 2010)

2. M. Kwietniewski, J. Rak, Niezawodność infrastruktury wodociagowej $i$ kanalizacyjnej $w$ Polsce (Wyd. Komitet Inżynierii Lądowej i Wodnej Polskiej Akademii Nauk, Warszawa, 2010)

3. E. Kuliczkowska, Instal, 11 (389), 70 - 74 (2017)

4. A. Kuliczkowski, E. Kuliczkowska, Przegląd budowlany, 3 (79), 31 - 34 (2008)

5. E. Kuliczkowska, K. Kotwica, NBI, 3(72), 86 - 88 (2017)

6. J. Dziopak, D. Słyś, A. Stec, Infrastruktura Miast (Oficyna Wydawnicza Politechniki Rzeszowskiej, Rzeszów, 95 - 122, 2017)

7. S. Daher, Defect - Based Condition Assessment Model and Protocol of Sewer Pipelines, MSc, Concordia University, Montreal, Quebec, Canada (2015) 
8. Water Research Centre (WRc), Manual of Sewer Condition Classification 5th Edition (2013)

9. K. Kaddoura, Automated Sewer Inspection Analysis and Condition Assessment, MSc, Concordia University, Montreal, Quebec, Canada (2015)

10. S. Rahman, D.J. Vanier, An Evaluation of Condition Assessment Protocols for Sewer Management (MIIP, NRCC, Client Report, B-5123.6, 2004)

11. S.E. McDonald, J.Q. Zhao, Condition assessment and rehabilitation of large sewers (International Conference on Underground Infrastructure Research, Univeristy of Waterloo, Waterloo, Ontario, June 10 - 13, 361 - 369 (2001)

12. J.Q. Zhao, S.E. McDonald, Y. Kleiner, Guidelines For Condition Assessment And Rehabilitation of Large Sewers (Institute for Research in Construction National Research Council Canada, Ottawa, Canada, K1A0R6 (2001)

13. New Zealand Water and Wastes Association Inc, New Zealand Pipe Inspection Manual 3rd Edition (2006)

14. National Association of Sewer Service Companies (NASSCO), Pipeline Assessment Certification Manual, Dallas (2015)

15. F. Chughtai, T. Zayed, J Infrastruct Syst, 17(3), 129 - 136 (2011)

16. E. Kuliczkowska, Kryteria planowania bezwykopowej odnowy nieprzełazowych przewodów kanalizacyjnych (Wyd. Politechniki Świętokrzyskiej, Kielce, 2008)

17. S. Han, H. Hwang, J. Korean Soc. Water Wastewater, 29 (1), 123 - 131 (2015)

18. H.D. Tran, Investigation Of Deterioration Models For Stormwater Pipe Systems, PhD, Victoria University (2007)

19. PN - EN 13508 - 2 Stan zewnętrznych systemów kanalizacyjnych. Część 2: System kodowania inspekcji wizualnej, Warszawa (2006)

20. M.J. Anbari, M. Tabesh, A. Roozbahani, J Environ Manage, 190, 91 - 101 (2017)

21. R. Błażejewski, Czasopismo Techniczne. Środowisko, 108 (1), 11 - 20 (2011)

22. J. Bailey, E. Keedwell, S. Djordjevic, Z. Kapelan, Ch. Burton, E. Harris, Procedia Eng, 119, 1288 - 1298 (2015)

23. K. Baah, B. Dubey, R. Harvey, E. McBean, Sci. Total Environ, 505, 1011 - 1017 (2015)

24. M. Halfawy, L. Dridi, S. Baker, Integrated Decision Support System for Optimal Renewal Planning of Sewer Networks (NRCC-50095, 2008)

25. M. Asgarian, M. Tabesh, A. Roozbahani, E.B. Bavani, IJst-T Civ Eng., 42(1), $55-71$ (2017)

26. Ch. Garrett, (No-Dig Conference, NASTT, Nashville, F-4-02-1, 2006)

27. E.C. Rossi, Criticality And Risk Assessment For Pipe Rehabilitation In The City Of Santa Barbara Sewer System, MSc, California Polytechnic State Univ. (2015)

28. M.G. Wade, (No-Dig Conference, NASTT, Washington D.C., TA-T6-05 2017)

29. B. Tchórzewska-Cieślak, J.R. Rak, Instal, 6(385), 63 - 67 (2017)

30. A. Królikowska, A. Królikowski, T. Żaba, Kanalizacja. Podstawy projektowania, wykonawstwa i eksploatacji (Wyd. Politechniki Krakowskiej, Kraków, 2015)

31. E. Kuliczkowska, Transp. Res. D, 48, 203 - 213 (2016)

32. E. Kuliczkowska, Environ Prot Eng, 44, 53 - 67 (2017)

33. E. Kuliczkowska, A. Parka, UFUG, 21, 1 - 10 (2017) 